\title{
ANÁLISE SEMIÓTICA DA REPRESENTAÇÃO ICONOGRÁFICA DE ELEMENTOS DE FUNÇÃO DE UM SISTEMA DE PROCESSADOR DE TEXTO
}

\author{
Ulisses Valadares Moreira da Silva ${ }^{1}$ \\ Cayley Guimarães ${ }^{2}$ - Orientador \\ 1.ulissesvaladares@.gmail.com; ${ }^{2}$ profcayley@yahoo.com.br; \\ Pós-Graduação em Comunicação Digital, Educação e Mídias Interativas - Uni-BH \\ (www.unibh.br)
}

\begin{abstract}
Resumo - Apresenta-se uma análise semiótica em que o objetivo é identificar e analisar características da construção visual que favorecem na sugestão para criação de icones mais inteligíveis para elementos de função do sistema de processador de texto: Word. 36 alunos voluntários do curso de Ciências da Computação do Centro Universitário de Belo Horizonte comprovaram a falta de usabilidade nesse sistema. Esse grupo é formado por usuários sofisticados e se esses ícones não são identificáveis por eles, com certeza terão menos significado para um usuário sem experiência. A linguagem digital deve obedecer a certos parâmetros para que os ícones sejam identificáveis pelos usuários. É difícil generalizar esses ícones, pois, baseando nos estudos da semiótica ou nos processos de semiose, o significado para um não é o mesmo para outro. Pretendeu-se chegar numa linguagem digital que tente alcançar seus significados identificáveis possíveis.
\end{abstract}

Palavras-chave - Semiótica. Ícone. Cognição. Interface. Metáfora. Gestalt

Abstract - He/she comes an analysis semiotics in that the objective is to identify and to analyze characteristics of the visual construction that favor in the suggestion for creation of more intelligible icons for elements of function of the word processor system: Word. 36 voluntary students of the course of Sciences of the Computation of the Academical Center of Belo Horizonte proved the usabilidade lack in that system. That group is formed by sophisticated users and if those icons are not identifiable for them, with certainty they will have meaning less for an inexperienced user. The digital language should obey certain parameters so that the icons are identifiable for the users. It is difficult to generalize those icons, because, basing on the studies of the semiotics or in the semiose processes, the meaning for one is not the same for other. It intended to arrive in a digital language him to try to reach their possible identifiable meanings.

Keywords - Semiotics. Icon. Cognition. Interface. Metaphor. Gestalt

\section{INTRODUÇÃO}

Os estudos de semiose e a preocupação no ambiente digital de uma interface que consiga transmitir o real significado de seus signos, faz com que surja oportunidades de análises semiótica de ícones que não conseguem sua representação na sua potencialidade. Para Peirce essa representação deve ser analisada desde a primeiridade e se necessário substituída por uma representação mais transparente.

\begin{abstract}
"O objeto da representação não pode ser outra coisa senão uma representação da qual a primeira representação é um interpretante. Mas uma série infinita de representações, cada qual representando a que está atrás de si, pode ser concebida como tendo um objeto no seu limite. $O$ significado de uma representação não pode ser senão uma representação. De fato, não é nada mais do que a representação, ela mesma, concebida como despida de roupagem irrelevante. Mas essa roupagem não pode ser nunca completamente despida; ela só é trocada por algo mais diáfano. Há, assim, uma regressão infinita aí (CP 1.339).
\end{abstract}

Na semiótica, os significados através dos representamens são diferentes de indivíduo para indivíduo. Esse artigo visa analisar esse propósito, pois, o uso apropriado de metáforas e ícones identificáveis e significativos pode reduzir a complexidade (Guimarães, 2008).

Sendo assim, o objetivo geral é identificar e analisar quais as características da construção visual que favorecem na criação de ícones mais inteligíveis. É necessário que se considere os significados obtidos não se esquecendo da cultura, da "bagagem" do indivíduo e principalmente do seu processo de cognição que é variável. Santaella (2000) nos diz que em alguns insights mais originais de Peirce, 
ele compara o juízo perceptivo às inferências abdutivas - a forma de raciocínio através da qual novas hipóteses são sugeridas.

\begin{abstract}
"A inferência abdutiva abriga-se no julgamento perceptivo sem uma linha firme de demarcação entre ambos; em outras palavras, nossas primeiras premissas, os julgamentos perceptivos devem ser considerados como casos extremos de inferência abdutiva” (CP 5.181).
\end{abstract}

Consequentemente, há um elemento hipotético em todo julgamento perceptivo. [...] Todos os julgamentos perceptivos são condicionados pelos princípios condutores $\mathrm{e}$ hábitos daquele que percebe. Isto não quer dizer que vemos algo que pode ser conhecido independentemente, e então colocamos uma interpretação sobre esse algo (cf. 8.65). [...] Se há um elemento hipotético envolvido em todo julgamento perceptivo é falível. A abdução por si mesma nunca nos fornece a validação necessária para testar a hipótese que ela sugere. "A abdução meramente sugere que algo pode ser” (CP 5.171).

Para que se consiga chegar a um resultado aproximado dos significados dos ícones é fundamental que se faça um estudo multidisciplinar permeando pelos conceitos da semiótica, da interface, do digital, dos ícones e da comunicação visual.

Um exemplo dessa necessidade é o ícone (na semiótica o termo que chamamos de ícone no ambiente digital são índices) do "disquete" no sistema de processador de texto: Word. O disquete que foi um método muito utilizado na década de 90 para "salvar" arquivos hoje perdeu seu significado semiótico através do processo de semiose da sociedade pós-moderna. Uma criança de aproximadamente 10 anos que usa o software Word com frequência, sabe que aquele ícone do disquete serve para "guardar" um arquivo. Mas, guardá-lo onde? O que é o disquete para ele? Com certeza, não querendo generalizar, o símbolo não quer dizer nada. É importante lembrar que ao salvar algum arquivo através desse ícone, o mesmo pode ser salvo em um pen drive, em um $\mathrm{CD}$ ou até mesmo na própria winchester do computador e utilizamos uma imagem que não condiz com o real processo. As metáforas utilizadas também são necessárias analisar, pois, nesse caso, utilizamos as palavras "salvar" ou "guardar" que no seu real significado não encontramos nada que se diz respeito ao ambiente digital. Outro exemplo interessante é do ícone da lata de lixo que é da cultura americana. Será que no Brasil o "saco de lixo" preto seria mais viável? Percebe-se nesse caso uma quebra de metáfora ao se jogar fora um arquivo que na verdade se deseja apagar.

A idéia da pesquisa escolhida partiu do artigo de Pio, F., \& Guimarães, C. (2006) que em sua pesquisa sobre a usabilidade e a interatividade de usuários com ícones de ecommerce, percebeu que mesmo ícones que possuem representações através de um objeto não são compreendidos na sua potencialidade.

Sendo assim, é fundamental analisar quais as características da construção visual que favorecem na criação de ícones mais inteligíveis. Propõe-se assim a atividade para que seja analisado o resultado da pesquisa.

\section{SISTEMA DE PROCESSADOR DE TEXTO: WORD}

O Word que foi criado por Richard Brodie é um processador de texto produzido pela Microsoft. Primeiramente fora criado para computadores IBM PC com o sistema operacional DOS em1983. Em seguida foram criadas versões para o Apple Macintosh (1984), SCO UNIX e Microsoft Windows (1989). Ele faz parte do conjunto de aplicativos Microsoft Office.

Por ter sido criado na década de 80 do século passado com certeza o sistema Word precisa passar por atualizações não somente nas 
técnicas de trabalho, mas, também de como essas técnicas estão disponíveis na sua interface.

A análise proposta irá trabalhar multisciplinarmente os conceitos de alguns pensadores sobre a semiótica, o ícone, a gestalt e a interface. Através dessa análise espera-se que a tese defendida comprove o viés dessa pesquisa de que os ícones do Microsoft Word precisem ser atualizados conforme as linguagens atuais.

\subsection{SEMiótica}

A palavra Semiótica veio do grego "Semeiotiké" ou a Arte dos Sinais. O termo foi originado da palavra Semeion que quer dizer signo.

Semiótica para Peirce é a visão que ele tem sobre lógica e filosofia da ciência na linguagem. Esta ciência estuda a produção de sentido nas diversas linguagens possibilitando assim a comunicação. Essa nem sempre é exata como a matemática, pois, trata-se de uma lógica filosófica da linguagem. É importante ressaltar que nessa filosofia estuda como que é que nós percebemos o mundo e como que comunicamos com ele.

"A sua semiótica (semeiótica, como ele preferia, respeitando as raizes gregas do termo) é, na verdade, uma teoria dos signos $e \quad d a$ representação que efetua uma extensão da Lógica para os limites da cognição $e$ da experiência dos fenômenos. É, por isso também uma teoria do conhecimento, além de propor novos insights sobre questões referentes à significação e à produção de sentido" (PINTO, 1995, p. 09 e 10).

Pinto em uma conferência da Série Pensadores para o Projeto Biblioteca Digital Multimídia exibida pela PUC TV no ano de 2008, disse que as representações, que também podem ser chamadas de signos, representam coisas que estariam no lugar de outras coisas. O signo é a matéria da linguagem. A linguagem escrita ou oral são todas compostas de coisas que estão no lugar de outras coisas. A linguagem tem representações abstratas que são apenas signos que nos representam uma coisa. A linguagem é um conjunto de signos que se destina ao estabelecimento de certas conexões, de certos vínculos com o mundo e com as coisas do mundo com base na troca de informações. Esses signos podem ser imagens, sons, um cheiro, um sabor, uma memória.

Ele complementou dizendo que não se pode pensar sem signos.

\begin{abstract}
"Não se pode comunicar sem signos. Os signos ao mesmo tempo que nos trazem o mundo, nos separam dele. Esses signos são mapeados com o mundo através da linguagem que pode nos trazer algumas conseqüências do ponto de vista do pensamento. Quando percebemos o mundo, percebemos em signos. Nossa percepção do mundo não é igual ao mundo. Minha percepção visual é diferente de todo mundo, pois, há certos desvios e distorções. Aquilo que o indivíduo percebe é determinado pela forma como ele percebe os signos e não exatamente pelo objeto que está emanado no signo” (PINTO, 2008).
\end{abstract}

No ambiente digital essas preocupações dos signos são bastante visíveis principalmente quando se trata de sua interface, pois, essa deve ser bem projetada para conseguir sua potencialidade.

“A interface bem projetada deve facilitar o uso e
possibilitar que a experiência seja fácil e
prazerosa. Ela deve ser transparente para o
usuário. Na Internet, essas qualidades são
estratégicas e de extrema importância para que
um produto obtenha sucesso" (MEMÓRIA, 2006,
p. 94).

Pensando-se nessa interface bem projetada os ícones tem uma função fundamental nesse processo. Segundo Loureiro (2006, p. 17), a função que o ícone desempenha nas interfaces gráficas vai além da simples requisição de determinada ação e acrescentou a importância da semiótica nesse estudo, pois, do ponto de vista conceitual, o ícone tem como objetivo produzir significados na interface, ou apontar caminhos e 
ações ou até mesmo ser uma ferramenta de comunicação. $\mathrm{O}$ ícone também produz significado para o usuário. $\dot{E}$ nas suas características de atribuição e de síntese que reside, o processo pelo qual o ícone se torna um meio de interação da interface. O difícil é a produção de ícones de elementos abstratos. Definam-se como ícones de elementos abstratos sendo aqueles que não tem uma representação material, mas, imaterial.

Representar um ícone de uma impressora é fácil e o ícone de formatação ou de e-mail que são elementos abstratos como representá-los? Dessa forma, os conceitos formulados pelo teórico Charles Sanders Peirce no início do século XX, a chamada Semiótica, fazem parte da análise desse elemento gráfico, que como conceito é parte integrante da teoria geral dos signos.

\section{2 ÍCONE}

O ícone é uma representação gráfica disponível em uma interface que tem como principal função interagir o usuário com o meio digital. Conforme Loureiro (2006) a utilização dos ícones nas interfaces foi um dos fatores que possibilitou a transposição da linguagem computacional para uma linguagem comum às pessoas sem conhecimento dos processos tecnológicos envolvidos. Ele acrescentou também que nesse processo, a utilização da metáfora foi crucial, já que, ela possibilita a compreensão de conceitos abstratos, por meio de correlações com conhecimentos familiares.

É fundamental que se pense na imagem desse ícone. Santaella (2001, p. 42) faz uma interrogação: "Será que as imagens podem ter significado diretamente como signos visuais, ou o significado da imagem só se origina pela mediação da linguagem?". Ela responde que tanto os aspectos da autonomia como também da interdependência entre linguagem e imagem devem ser levados em consideração.
Para Aumont (1993, p. 73 e 78) se a imagem for arbitrária, inventada, plenamente cultural, sua visão é quase imediata. Ele cita a reflexão de Rudolf Arnheim (1969) que propõe uma tricotomia sugestiva e cômoda entre valores da imagem em relação com o real:

a) Um valor de representação: a imagem representativa é a que representa coisas concretas ("de um nível de abstração inferior ao das próprias imagens"). A noção de representação é capital, e a ela voltaremos detalhadamente, contentando-nos agora em supô-la conhecida pelo menos em suas grandes linhas.

b) Um valor de símbolo: a imagem simbólica é a que representa coisas abstratas (“de um nível de abstração superior ao das próprias imagens").

c) Um valor de signo: para Arnheim, uma imagem serve de signo quando representa um conteúdo cujos caracteres não são visualmente refletidos por ela. $\mathrm{O}$ exemplo característico continua a ser o das placas de sinalização - ao menos de certas placas - do código rodoviário francês, como o fim do limite de velocidade (barra oblíqua azul escuro em fundo marfim), cujo significante visual tem uma relação totalmente arbitrária com seu significado.

\subsection{Gestalt do OBJETO OU DA IMAGEM}

A Escola de Psicologia Experimental Gestalt, localizada na Alemanha, fez no início do século XX um estudo detalhado sobre o processo de percepção de imagens pelo sistema visual humano que criou leis gerais de percepção que foram denominadas Leis da Gestalt.

Segundo Gomes Filho (2000) por ser uma expressão gráfica e que para que essa tenha sucesso no processo de comunicação e um máximo entendimento do usuário, devem de ser aplicadas algumas técnicas visuais impostas nas Leis da Gestalt, sendo elas: 
a) Clareza: o uso da harmonia, do equilíbrio e da ordem, possibilita a facilidade de leitura e rapidez na decodificação e/ou compreensão imediata do objeto.

b) Simplicidade: a mente humana tende a organizar da forma mais harmoniosa e unificada possível o que o olho vê. A simplicidade se caracteriza por organizações formais fáceis de serem assimiladas, lidas e compreendidas rapidamente.

c) Minimidade: consiste em aplicar apenas o essencial, diminuindo ao máximo o uso de unidades e elementos informacionais.

Aumont (1993, p. 93) ao citar as teses gestaltistas de Arnheim disse que em toda a literatura de inspiração gestaltista sobre a imagem, encontra-se o tema da apreensão da imagem pelo espectador como descoberta que ele faz na imagem de estruturas profundas que são as próprias estruturas mentais: idéia, como se vê, que é totalmente coerente com a abordagem gestaltista em geral, para a qual a percepção do mundo é um processo de organização, de ordenamento de dados sensoriais para torná-los conformes com certa quantidade de grandes categorias e de "leis" inatas que são as de nosso cérebro. Aumont (1993, p. 93 e 94) sugere uma análise de duas sugestões na obra de Arnheim:

a) $O$ pensamento visual: Ao lado do pensamento verbalizado, formado e manifestado pela mediação deste artefato humano que se chama linguagem, há espaço, segundo ele, para um modo de pensamento mais imediato, que não passa ou, pelo menos, não passa inteiramente pela linguagem, mas que se organiza, ao contrário, diretamente a partir dos perceptos dos nossos órgãos dos sentidos: o pensamento sensorial. Entre esses atos de pensamento, é privilegiado o pensamento visual: de todos os nossos sentidos, a visão é o mais intelectual, o mais próximo do pensamento (...), e talvez o único cujo funcionamento esteja de fato próximo ao do pensamento. b) O centramento subjetivo: Boa parte das reflexões de Arnheim sobre a imagem baseia-se na idéia de que o espectador tem uma concepção subjetivo-centrada do espaço que o circunda. Arnheim propôs descrever o espaço representativo, não de acordo com a geometria cartesiana, objetiva, mas segundo uma geometria subjetiva, de coordenadas polares (isto é, definidas por um centro, o sujeito que olha, duas coordenadas angulares que situam a direção olhada em relação a esse centro, horizontal e verticalmente, e uma terceira coordenada que é a distância do objeto olhado ao centro).

Sendo assim, é necessário que o Web Designer tenha conhecimentos teóricos sobre a imagem e sobre a percepção humana antes da construção dos ícones, pois, deve-se levar em consideração a percepção do usuário, o modo como este usuário utiliza o computador, seu contexto social, tecnológico e cultural e a forma que esse usuário se comunica.

\subsection{INTERFACE}

Com o avanço tecnológico na década de $80 \mathrm{fez}$ com que o modelo padrão de comunicação fosse atualizado no que se diz respeito na relação entre o usuário e o computador. Essa interação começou a ser intercedida pela interface gráfica chamada de GUI (Graphical User Interface) que para Mandel (1997) determina como "representação gráfica e interação com programas, informações e objetos na tela do computador". Com essa atualização os computadores passaram a ser acessíveis não somente pelos usuários "sofisticados", mas, também, pelos menos "sofisticados". Pois, com essa nova linguagem, ou, esse novo formato de comunicação através dos ícones, as janelas, as barras de rolagem, botões, caixas de texto, etc; fez com que a falta de usabilidade fosse diminuída.

\section{Metodologia}


A análise foi feita com 36 alunos voluntários do Centro Universitário de Belo Horizonte que tem conhecimento em informática. Esse grupo pode até influenciar no resultado da pesquisa, mas, é importante ressaltar que se são usuários "sofisticados" e não conseguem definir os significados dos ícones apresentados, fica comprovado a tese defendida da falta de usabilidade e da necessidade da atualização dos ícones conforme a "nova linguagem" digital.

\subsubsection{ETAPA I - APRESENTAÇÃO DOS ÍCONES}

$\mathrm{Na}$ apresentação dos ícones com suas respectivas metáforas e funções aos voluntários, é evidente confirmar que conforme as análises semióticas o processo de cognição irá variar de pessoa para pessoa. Essa variação segundo Santaella (1983, p. 42), Peirce classificaria como primeiridade, secundidade e terceiridade.

a) Primeiridade: Nessa fase o indivíduo percebe a "coisa" conforme sua "bagagem", ou seja, digamos sua qualidade de vivência. A Primeiridade refere-se a tudo que está presente à consciência naquele instante. Refere-se a todo aspecto de qualidade que vivenciar tal experiência. O primeiro é espontâneo e imediato, original e livre. Primeiridade é a compreensão superficial de um texto (uma foto pode ser lida, por exemplo). A primeiridade consiste, por exemplo, na presença de imagens diretamente à consciência, sem uma consciência propriamente dita; melhor argumentando, "trata-se, pois, de uma consciência imediata tal qual é. Nenhuma outra coisa senão pura qualidade de sentir. A qualidade da consciência imediata é uma impressão In totum, indivisível, não analisável, inocente e frágil".(Santaella, 1983, p. 43).

Sendo assim, para que uma pessoa consiga ler ou interpretar um ícone é necessária essa primeiridade sígnica para que o processo da secundidade e da terceiridade tenha êxito. Não só esse insight proposto por Peirce, mas, a linguagem, a comunicação em geral. b) Secundidade: A secundidade é a reflexão envolvida nesse processo. É quando a pessoa lê com profundidade e compreende o seu conteúdo. $\mathrm{O}$ observador faz uma comparação com experiências e situações vividas por ele. No caso dessa análise semiótica seria o índice do ícone. "Secundidade é aquilo que dá à experiência seu caráter factual, de luta e confronto" (Santaella, 1983, p. 51).

$\mathrm{Na}$ análise proposta dos ícones é como se uma pessoa olhasse para o ícone (sua imagem) e não a conhecesse, esse imediatamente fará reflexões e comparações de algo já visto ou vivido por ele.

c) Terceiridade: A terceiridade é a reflexão que você fará (pode ser uma ação, uma reflexão etc). É o pensamento em signos, a qual representamos e interpretamos. De acordo com Santaella (1983, p. 51), no nível do pensamento a terceiridade corresponderia ao nível simbólico, sígnico, onde representamos e interpretamos o mundo.

Se soubermos a relação que a imagem de um ícone tal tem com a sua função e a sua metáfora, o processo do insight de Peirce tornase autêntico. Mas, é fundamental que saibamos que esse processo é infinito, ou seja, de acordo com Pinto (2008) dentro da primeiridade têm-se a secundidade e a terceiridade; dentro da secundidade têm-se a primeiridade, a secundidade e a terceiridade; dentro da terceiridade têm-se a primeiridade, a secundidade e a terceiridade; e assim sucessivamente. Pelo esquema abaixo fica mais fácil de entender essa analogia.

$$
\begin{gathered}
1-1 / 2 / 3 \ldots \\
1-2-1 / 2 / 3 \ldots \\
3-1 / 2 / 3 \ldots \\
\\
1-1 / 2 / 3 \ldots \\
2-2-1 / 2 / 3 \ldots
\end{gathered}
$$




$$
3-1 / 2 / 3 \ldots
$$

$$
1-1 / 2 / 3 \ldots
$$

$3-2-1 / 2 / 3 \ldots$

$$
3-1 / 2 / 3 \ldots
$$

Essa analogia ajudou o autor a elaborar e dar nome a um de seus livros, que se chama: 1 , 2, 3 da Semiótica. Ou seja, todo alicerce semiótico está fundamentado na simples relação do $1,2,3$. Na análise proposta o ícone, a função e a metáfora torna-se um exemplo dessa relação do 1, 2, 3. É válido ressaltar que se cada indivíduo possui a sua cognição diferente de outro indivíduo essa relação do 1, 2, 3 existirá, porém, como no esquema acima esses podem vir à sua mente de maneira não linear.

Antes das sugestões dos ícones seguem-

\begin{tabular}{|c|c|c|c|}
\hline $\begin{array}{l}\text { FUNÇÃO } \\
\text { \% ACERTO }\end{array}$ & $\begin{array}{c}\text { SIGNIFICA } \\
\text { DO }\end{array}$ & $\begin{array}{c}\text { METÁFORA } \\
\% \text { ACERTO }\end{array}$ & ÍCONES \\
\hline $\begin{array}{l}\text { Salvar um } \\
\text { documento }\end{array}$ & Disquete & $\begin{array}{l}\text { Um disquete } \\
\text { transmitindo a } \\
\text { idéia de salvar } \\
\text { um arquivo }\end{array}$ & 回 \\
\hline $\begin{array}{l}\text { Abrir um novo } \\
\text { documento }\end{array}$ & $\begin{array}{c}\text { Folha nova em } \\
\text { branco }\end{array}$ & $\begin{array}{c}\text { A folha nova } \\
\text { transmite a idéia } \\
\text { de um novo } \\
\text { documento }\end{array}$ & \\
\hline $\begin{array}{c}\text { Abrir um } \\
\text { documento já } \\
\text { existente }\end{array}$ & Pasta Suspensa & $\begin{array}{c}\text { Uma pasta } \\
\text { suspensa sendo } \\
\text { aberta para } \\
\text { buscar } \\
\text { documentos já } \\
\text { existentes }\end{array}$ & 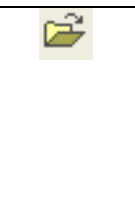 \\
\hline $\begin{array}{c}\text { Abrir o } \\
\text { Microsoft } \\
\text { Outlook }\end{array}$ & $\begin{array}{l}\text { Carta com o seu } \\
\text { envelope }\end{array}$ & $\begin{array}{l}\text { Metáfora de uma } \\
\text { carta aberta } \\
\text { indicando que } \\
\text { existe uma } \\
\text { mensagem }\end{array}$ & 间 \\
\hline $\begin{array}{l}\text { Pesquisar por } \\
\text { arquivos } \\
\text { existentes por } \\
\text { palavra chave }\end{array}$ & $\begin{array}{l}\text { Lupa posterior a } \\
\text { uma folha } \\
\text { branca com o } \\
\text { símbolo da } \\
\text { Microsoft }\end{array}$ & $\begin{array}{l}\text { A lupa mostra a } \\
\text { intenção da } \\
\text { procura de algo } \\
\text { em um } \\
\text { documento }\end{array}$ & 昌 \\
\hline
\end{tabular}
se abaixo as funções, as metáforas e os ícones

\begin{tabular}{|c|c|c|c|}
\hline Imprimir & $\begin{array}{c}\text { Impressora } \\
\text { matricial }\end{array}$ & $\begin{array}{c}\text { Nos remete a } \\
\text { idéia de imprimir } \\
\text { algo }\end{array}$ & 晋 \\
\hline $\begin{array}{l}\text { Ver detalhes do } \\
\text { documento em } \\
\text { trabalho }\end{array}$ & $\begin{array}{c}\text { Lupa posterior a } \\
\text { uma folha } \\
\text { branca }\end{array}$ & $\begin{array}{l}\text { A lupa mostra a } \\
\text { intenção da } \\
\text { procura de algo } \\
\text { em um } \\
\text { documento }\end{array}$ & \\
\hline $\begin{array}{c}\text { Verificar } \\
\text { ortografia e } \\
\text { gramática }\end{array}$ & $\begin{array}{l}\text { Letras com um } \\
\text { visto }\end{array}$ & $\begin{array}{c}\text { As letras com um } \\
\text { visto da a idéia de } \\
\text { que a palavra está } \\
\text { correta }\end{array}$ & $\sqrt[A B C]{ }$ \\
\hline $\begin{array}{l}\text { Colar um } \\
\text { documento já } \\
\text { copiado }\end{array}$ & $\begin{array}{c}\text { Prancheta com } \\
\text { uma folha } \\
\text { escrita }\end{array}$ & $\begin{array}{l}\text { Metáfora de um } \\
\text { documento } \\
\text { escrito sendo } \\
\text { retirado ou } \\
\text { colocado na } \\
\text { prancheta }\end{array}$ & 唲 \\
\hline $\begin{array}{c}\text { Alinhar o texto à } \\
\text { esquerda }\end{array}$ & 6 Linhas digitais & $\begin{array}{c}6 \text { Linhas } \\
\text { indicando } 3 \text { delas } \\
\text { mais à esquerda }\end{array}$ & 竎 \\
\hline $\begin{array}{c}\text { Centralizar o } \\
\text { texto }\end{array}$ & 6 linhas digitais & $\begin{array}{c}6 \text { linhas } \\
\text { indicando } 3 \text { delas } \\
\text { centralizadas }\end{array}$ & \\
\hline $\begin{array}{c}\text { Alinhar o texto à } \\
\text { direita }\end{array}$ & 6 linhas digitais & $\begin{array}{c}6 \text { linhas } \\
\text { indicando } 3 \text { delas } \\
\text { mais à direita }\end{array}$ & $\bar{\equiv}$ \\
\hline Justificar o texto & 6 linhas digitais & $\begin{array}{c}6 \text { linhas } \\
\text { indicando as } 6 \\
\text { iguais na } \\
\text { formatação }\end{array}$ & \\
\hline $\begin{array}{c}\text { Solucionar } \\
\text { problemas ou } \\
\text { dúvidas }\end{array}$ & $\begin{array}{c}\text { Um ponto de } \\
\text { interrogação } \\
\text { superior a uma } \\
\text { caixa de diálogo }\end{array}$ & $\begin{array}{c}\text { O ponto de } \\
\text { interrogação } \\
\text { indica que há } \\
\text { uma dúvida } \\
\text { existente ou um } \\
\text { problema a ser } \\
\text { solucionado }\end{array}$ & ?? \\
\hline
\end{tabular}
que foram apresentados aos voluntários.
TABELA 1 - APRESENTAÇão DOS ÍCONES

\subsubsection{ETAPA II - ATUALIZAÇão DOS Í́CONES}

Pelo fato dos alunos já serem usuários do sistema Word e terem um conhecimento avançado, o acerto das funções e das metáforas de alguns ícones foi mais fácil, mas, não descartaram que o sistema precisa ser atualizado conforme a "nova linguagem" digital, os novos formatos de mídia e a nova contextualização sócio-cultural da sociedade. 


\subsubsection{RESUlTAdOS E ANÁlise dA ETAPA II}

Nesta etapa os voluntários sugeriram que os ícones fossem atualizados, e, a partir destas sugestões, e de uma análise semiótica, chegou-se a um conjunto comum de ícones sugeridos, conforme na tabela abaixo:

\begin{tabular}{|c|c|c|c|}
\hline FUNÇÃo & METÁFORA & ÍCONES & $\begin{array}{l}\text { ÍCONES } \\
\text { SUGERI- } \\
\text { DOS }\end{array}$ \\
\hline $\begin{array}{ll}\text { Salvar } & \text { um } \\
\text { documento } & \end{array}$ & $\begin{array}{l}\text { Um disquete } \\
\text { transmitindo a } \\
\text { idéia de salvar } \\
\text { um arquivo }\end{array}$ & 足 & AVE \\
\hline $\begin{array}{l}\text { Abrir um novo } \\
\text { documento }\end{array}$ & $\begin{array}{l}\text { A folha nova } \\
\text { transmite a idéia } \\
\text { de um novo } \\
\text { documento }\end{array}$ & & $\begin{array}{l}\text { NEW } \\
\text { DOC }\end{array}$ \\
\hline $\begin{array}{c}\text { Abrir um } \\
\text { documento já } \\
\text { existente }\end{array}$ & $\begin{array}{c}\text { Uma pasta } \\
\text { suspensa sendo } \\
\text { aberta para } \\
\text { buscar } \\
\text { documentos já } \\
\text { existentes }\end{array}$ & $\theta^{2}$ & \\
\hline $\begin{array}{c}\text { Abrir o } \\
\text { Microsoft } \\
\text { Outlook }\end{array}$ & $\begin{array}{c}\text { Metáfora de } \\
\text { uma carta aberta } \\
\text { indicando que } \\
\text { existe uma } \\
\text { mensagem }\end{array}$ & 间 & \\
\hline $\begin{array}{l}\text { Pesquisar por } \\
\text { arquivos } \\
\text { existentes por } \\
\text { palavra chave }\end{array}$ & $\begin{array}{l}\text { A lupa mostra a } \\
\text { intenção da } \\
\text { procura de algo } \\
\text { em um } \\
\text { documento }\end{array}$ & 成 & \\
\hline Imprimir & $\begin{array}{l}\text { Nos remete a } \\
\text { idéia de } \\
\text { imprimir algo }\end{array}$ & 鞄 & \\
\hline $\begin{array}{l}\text { Ver detalhes do } \\
\text { documento em } \\
\text { trabalho }\end{array}$ & $\begin{array}{l}\text { A lupa mostra a } \\
\text { intenção da } \\
\text { procura de algo } \\
\text { em um } \\
\text { documento }\end{array}$ & 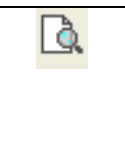 & \\
\hline $\begin{array}{c}\text { Verificar } \\
\text { ortografia e } \\
\text { gramática }\end{array}$ & $\begin{array}{l}\text { As letras com } \\
\text { um visto da a } \\
\text { idéia de que a } \\
\text { palavra está } \\
\text { correta }\end{array}$ & $\sqrt[A B C]{ }$ & \\
\hline
\end{tabular}

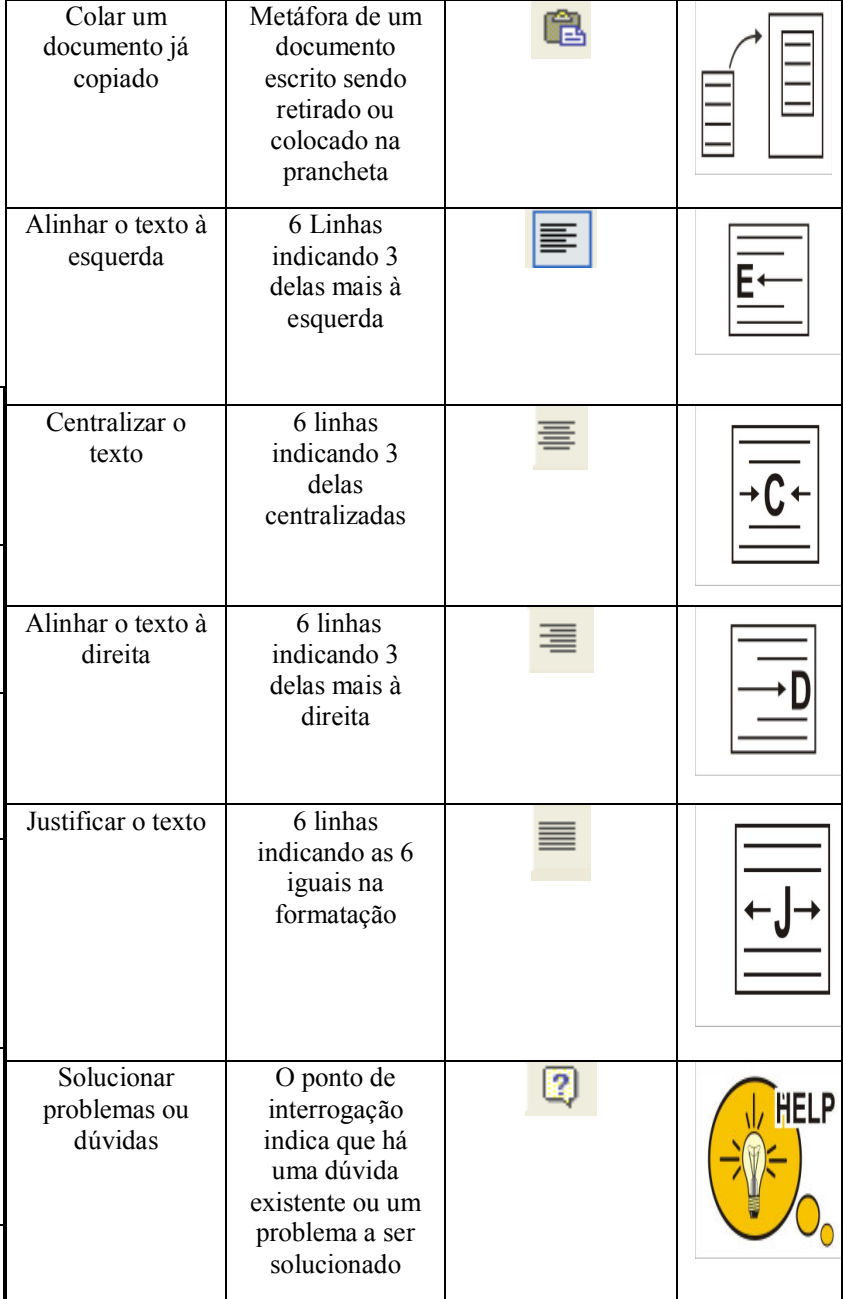

\section{TABELA 2 - SUGESTÕES DE ÍCONES}

De acordo com os voluntários, os ícones sugeridos acima são os que mais condizem com a atual linguagem digital.

\subsubsection{ANÁLISE SEMIÓTICA DAS SUGESTÕES DOS ÍCONES}

Os ícones sugeridos são um consenso, obtido através da análise semiótica, das sugestões dos pesquisados. Como trabalho futuro, eles devem ser testados para verificar se o interpretante concorda, e se consegue obter um significado condizente com a tarefa a ser executada. 
Apesar de que alguns ícones como o disquete que tem a função de "salvar" e a impressora que tem a função de "imprimir" já serem bastante conhecidos pelos voluntários, os mesmos concordaram que os ícones devem de ser atualizado, pois, hoje, não se usa mais disquetes para "salvar" arquivos e esporaticamente vemos uma impressora matricial.

O que é fundamental ressaltar nessa análise foi o processo semiótico de cada voluntário na decisão do formato e características de cada ícone. As reações, ou seja, as cognições variaram entre o grupo.

Segundo Santaella (1983), Peirce classificaria essa análise das cognições de cada indivíduo como primeiridade, secundidade e terceiridade que se reflete diretamente no conceito de Ícone, Índice e Símbolo. Para Santaella (2000, pág. 109), se o signo tem uma propriedade monádica (qualidade, primeiridade), então ele é um ícone do objeto. Uma vez que a propriedade monádica é não-relacional, a única relação possível que o ícone pode ter com seu objeto, em virtude de tal propriedade, é aquela de ser idêntico a seu objeto.

\begin{abstract}
"Um Ícone é um Signo que se refere ao Objeto que denota apenas em virtude de seus caracteres próprios, caracteres que ele igualmente possui, quer tal Objeto exista ou não. É certo que, a menos que realmente exista um tal Objeto, o Ícone não atua como signo. Qualquer coisa, seja uma qualidade, um existente individual ou uma lei, é o Ícone de qualquer coisa, na medida em que for semelhante a essa coisa e utilizado como um signo seu" (CP 2.247).
\end{abstract}

Segundo Santaella (2000, pág. 121), os Índices são os tipos de signos que podem ser mais fartamente exemplificados. Diferentemente dos ícones que, para funcionarem como signos, dependem de hipotéticas relações de similaridade, também diferentes das abstrações gerais que comandam o universo dos símbolos, os índices são prioritariamente sin-signos com os quais estamos continuamente nos confrontando nas lidas da vida.

Eles são afetados por existentes igualmente singulares, seus objetos, para os quais os sin-signos remetem, apontam, enfim, indicam.

\begin{abstract}
"Índice: um signo ou representação que se refere a seu Objeto não tanto em virtude de uma similaridade ou analogia qualquer com ele, nem pelo fato de estar associado a caracteres gerais que esse objeto acontece ter, mas sim por estar numa conexão dinâmica (espacial, inclusive) $\mathrm{com}$ o Objeto" [...] (CP 2.305).
\end{abstract}

Santaella (2000, pág. 132) diz que o Símbolo é um signo cuja virtude está na generalidade da lei, regra, hábito ou convenção de que ele é portador e a função como signo dependerá precisamente dessa lei ou regra que determinará seu interpretante.

Sendo assim, nesta análise semiótica, nos mostra mais uma vez da necessidade dessa atualização dos ícones do Word, pois, existem cognições diferentes que fazem com que os índices dos ícones variem de indivíduo para indivíduo. O ícone que estamos trabalhando torna-se não ícone, mas, índice, pois, este aponta para uma função tal.

A "nova linguagem" digital, os novos formatos de mídia e a nova contextualização sócio-cultural da sociedade fazem com que as funções e as metáforas dos ícones necessitem de uma atualização para que estas possuem um significado condizente com a atualidade.

\section{CONCLUSÃo}

Pode-se concluir através de todas as etapas executadas que realmente o sistema do Microsoft Word necessita de algumas atualizações em sua interface. Os voluntários concordaram que atualmente não existe um 
consistente encontro entre os significados e as funções impostas, ou seja, para eles os usuários atuais terão dificuldades de compreender 0 significado correto dos ícones e de suas respectivas funções. Isso se comprova pelo fato dos voluntários serem usuários "sofisticados" e perceberem a necessidade da atualização dos ícones conforme a "nova linguagem" digital, os novos formatos de mídia e a nova contextualização sócio-cultural da sociedade.

É válido lembrar que os ícones devem ser atualizados conforme as linguagens atuais para que o usuário possa entender o significado do ícone e/ou da função, pois, senão, pode não conseguir usar. Não são os usuários que têm que mudar para usar os computadores e seus softwares, mas estes que têm que se adequar às suas necessidades.

\section{Agradecimentos}

$\mathrm{O}$ autor reconhece que, ao realizar qualquer trabalho, recebem influências e acatam sugestões de pessoas que contribuem para a elaboração do mesmo. Sendo assim, agradeço ao Uni-BH pela publicação da Revista Eletrônica POC e aos alunos pela seriedade e empenho em desenvolverem trabalhos dentro do padrão especificado. Sou grato, também, à equipe de orientadores, que exercem a função de docência com responsabilidade, dignidade e segurança, em especial ao professor Cayley Guimarães pelas sugestões apresentadas durante a realização deste trabalho, pelo apoio e confiança irrestritos.

\section{REFERÊNCIAS}

AUMONT, Jacques. A imagem. Campinas (SP). Editora Papirus, 1993.

GOMES FILHO, João. Gestalt do objeto: sistema de leitura visual da forma. São Paulo: Escrituras, 2000.
GUIMARAES, C.. Usabilidade no dia-a-dia: Interação de Seres Humanos com Sistemas. Belo Horizonte: Fundac - BH, 2008. 396 p.

GUIMARAES, C.; PIO, F.. E-commerce - Qual ícone é a alma do negócio. In: SBC / IV SBSI, 2008, Rio de Janeiro. Anais do SBC / IV SBSI 2008, 2008.

LÉVY, Pierre. Cibercultura. $2^{\mathrm{a}}$ edição. São Paulo: Editora 34, 2000.

LOUREIRO, Eduardo Pinheiro. O ícone interfacial: Estudo e análise conceitual e tecnológica. Monografia de Graduação em Comunicação Social com habilitação em Produção Editorial. Belo Horizonte - MG. UNIBH (Centro Universitário de Belo Horizonte), 2006.

MANDEL, Theo. The elements of user interface design. New York: John Wiley \& Sons, Inc., 1997.

MEMÓRIA, Felipe. Design para a internet. Rio de Janeiro: Elsevier, 2006.

PEIRCE, C. S. Semiótica. $3^{a}$ edição. São Paulo: Perspectiva, 2000.

PEIRCE, C.S. Collected papers. C. Hartshorne e P. Weiss. Eds. (v. 1-8) e A. W. Burks. Ed. (v. 78). Cambridge, MA, Harvard University Press (aqui referido como $\mathrm{CP}$; os números das citações referem-se respectivamente aos volumes e parágrafos), 1931-58.

PINTO, Júlio. 1,2,3 da Semiótica. Belo Horizonte - MG: UFMG, 1995.

PIO, F.; GUIMARAES, C.. E-commerce: Qual ícone vale mais que mil palavras? In: SBC/IV SMSI, 2007, Lavras. SBC / IV SMSI, 2007.

SANTAELLA, Lúcia. Culturas e artes do póshumano. $2^{\mathrm{a}}$ edição. São Paulo: Paulus, 2003.

SANTAELLA, Lúcia. A teoria geral dos signos: Como as linguagens significam as coisas. $1^{\mathrm{a}}$ edição. São Paulo: Pioneira Thomson Learning, 2000. 
SANTAELLA, Lúcia. Imagem: Cognição, http://www.youtube.com/watch?v=5msemiótica, mídia. $3^{a}$ edição. São Paulo: Editora ivyRZ4lo. Acesso em 25 de Agosto/2008.

Iluminuras, 2001.

SANTAELLA, Lúcia. O que é semiótica. $1^{\text {a }}$ http://www.youtube.com/watch?v=IN2anWS0b5 edição: Coleção Primeiros Passos. São Paulo: Editora Brasiliense, 1983.

\section{DOCUMENTOS ELETRÔNICOS}

I. Acesso em 25 de Agosto/2008.

http://www.youtube.com/watch?v=Irkymh3K3Z Q. Acesso em 25 de Agosto/2008.

http://www.youtube.com/watch?v=bP2maOFRr RE. Acesso em 25 de Agosto/2008.

http://www.eduardoloureiro.com/Monografia_E duardoLoureiro 2006.pdf. Acesso em 24 de Agosto/2008.

http://www.youtube.com/watch? $\mathrm{v}=\mathrm{mFm} 7 \mathrm{LWeY}$ $\underline{\mathrm{KtY}}$. Acesso em 25 de Agosto/2008.

http://www.youtube.com/watch?v=frchrXktyJw. Acesso em 25 de Agosto/2008.

http://www.youtube.com/watch?v=vziVoWUJY Ik. Acesso em 25 de Agosto/2008.

http://www.youtube.com/watch?v=bVhTRsRBR 3g. Acesso em 25 de Agosto/2008.

http://www.youtube.com/watch?v=TGbBWoS3J Os. Acesso em 26 de Agosto/2008.

http://www.youtube.com/watch? $\mathrm{v}=\mathrm{JU}$ lwIwvUm ZM. Acesso em 26 de Agosto/2008.

http://www.youtube.com/watch?v=Zn42PxTPM rU. Acesso em 29 de Agosto/2008.

http://pt.wikipedia.org/wiki/Microsoft Word. Acesso em 26 de Maio/2009.

http://amandaveronese.wordpress.com/2008/03/ 17/primeiridade-secundidade-terceiridade/ . Acesso em 08 de Junho/2009.

http://www.youtube.com/watch? $\mathrm{v}=\mathrm{ohHKK}$ -

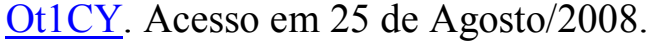

